\title{
Saberes matemáticos produzidos pelos produtores rurais da comunidade camponesa em suas práticas cotidianas
}

\author{
Mathematical learnings produced by the rural producers of the country \\ community in its everyday practices
}

\author{
Paulo Policarpo Campos ${ }^{1}$ \\ paulpolicarpocampos@hotmail.com
}

\begin{abstract}
Resumo
O presente artigo é parte de uma Dissertação de Mestrado $^{2}$, sendo realizado com o objetivo de analisar os saberes matemáticos produzidos e praticados nas atividades cotidianas de um grupo de produtores rurais do Movimento Sem Terra (MST), referenciado ao longo deste estudo de em uma Comunidade Camponesa. Os referenciais teóricos utilizados advém do campo da Etnomatemática e das perspectivas contemporâneas do Currículo. $\mathrm{O}$ procedimento e método utilizados na parte empírica da investigação, de inspiração etnográfica, envolveu a entrevista estruturada. Em síntese, esste estudo possibilitou compreender que os saberes matemáticos que são produzidos em situações cotidianas, não são incorporados pelo currículo escolar, e continuam de certa forma ainda relegados à ignorância.
\end{abstract}

Palavras-chave: Etnomatemática. Comunidade Camponesa. Saberes matemáticos. Atividades Cotidianas. Currículo.

\begin{abstract}
The current article is part of my Master's Degree Dissertation. It was made with the aim of analyzing the mathematical learnings produced and practiced in the everyday practices by a group of rural producers of the Landless Movement (MST), referred along this study in Country Community. The theoretical references come from the Ethnomathematics field and from contemporary prospects of the Curriculum. The procedure and method utilized in the empirical part of the investigation of ethnographic inspiration involved the structured interview. In short, this study enabled to understand that the mathematical learnings which are produced in everyday situations are not incorporated by the school curriculum, and they continue in a certain way relegated to ignorance.
\end{abstract}

Keywords: Ethnomathematics - Country Community - Mathematical Learnings - Everyday Activities Curriculum.

\footnotetext{
${ }^{1}$ Mestrando em Ensino das Ciências pela UFRPE e professor no curso de graduação em Matemática pela FAFOPST. (paulopolicarpocampos@ hotmail.com).

${ }^{2}$ A matemática do meio rural numa abordagem etnomatemática: uma experiência educacional dos NúcleosEscolas da Comunidade Camponesa do Movimento Sem Terra no município de Serra Talhada.
} 


\section{Introdução}

Há muito tempo o Ensino de Matemática vem sendo questionado por pais, alunos e professores, devido a dificuldade apresentada pelos alunos na compreensão dessa disciplina em sala de aula, que tem avançado de forma crescente. Santos (2007) comenta que essa situação tem levado profissionais da área a repensarem o seu papel e a buscarem alternativas que possibilitem a reversão desse quadro. Acredita-se que uma abordagem metodológica que tenha como pressuposto a valorização do conhecimento matemático que emerge de comunidades socialmente distintas pode ser desenvolvida no currículo escolar, de forma a tornar o ensino de matemática mais contextualizado com valorização e preocupações de natureza socioculturais. De acordo com D’Ambrosio (1990), isso significa construir condições para que o aluno possa lidar com situações diversas no seu cotidiano, o que não se obtém apenas fazendo contas e resolvendo problemas que não tem significado para os alunos.

As escolas, tradicionalmente, se organizam de modo a desenvolver os mesmo conteúdos de matemática nas mesmas séries, indiferentes às necessidades e aos interesses de aprendizagem dos alunos. Isso ocorre porque o ensino da matemática é fortemente influenciado pela cultura ocidental, identificada como uma Etnomatématica Ocidental (D’ÁMBROSIO, 2002).

Segundo D’Ambrosio (1996, p.73), a disciplina identificada como Matemática é, na verdade, uma Etnomatemática que se originou na Europa, a partir de tradições do Egito, da Babilônia e da Judéia, assimilada e desenvolvida pelos gregos e, posteriormente, pelos árabes, com algumas contribuições da civilização hindu e romana, que chegou ao século XVI produzindo uma transformação no pensamento europeu e atingindo a sua forma atual nos séculos XVII e XIX. Ela foi levada e imposta a todo mundo, sendo atualmente detentora de um caráter universal, ainda.

Atualmente, os estudos da Etnomatemática têm sido direcionados para a análise da atuação de profissionais de diversas áreas ou para propostas desenvolvidas para certos grupos sociais. Delfino (2007), por exemplo, estudou pedreiros da construção civil, analisando a presença da matemática desde a avaliação dos materiais usados até a execução da obra. Da mesma forma, Abreu (1988), por exemplo, estudou um grupo de produtores de cana-de-açúcar, analisando a natureza e o uso da matemática na vida diária desses produtores rurais. Knijnik (2003), por sua vez, apresenta a experiência obtida em um assentamento do Movimento Sem Terra do Rio Grande do Sul, a partir de um projeto pedagógico centrado em uma das atividades mais produtivas da comunidade, o plantio de alface. Este projeto foi desenvolvido com alunos da $7^{\mathrm{a}}$ 
série, a professora de Matemática, as famílias assentadas e o agrônomo que fez o acompanhamento do assentamento.

Nesse sentido, Rosa e Orey (2004) manifestam a importância da implementação da Etnomatemática para o ensino de matemática nas escolas, proporcionando aos alunos uma vivencia que realmente faça sentido.

Em consonância com essas considerações, esta pesquisa tem o objetivo de analisar os saberes matemáticos produzidos e praticados nas atividades cotidianas de um grupo de produtores rurais do Movimento Sem Terra (MST), referenciado ao longo deste estudo de Comunidade Camponesa.

\title{
2. Pressupostos teóricos
}

Inicialmente é apresentada a posição de autores renomados, e do pesquisador, a respeito do significado de Etnomatemática, para que, partindo deste significado, se possa refletir com mais clareza sobre a prática do contexto cotidiano ao contexto escolar.

\subsection{Dando sentido a Etnomatemática: Etnomatemática fazendo sentido}

Ubiratan D'Ambrosio oferece um exemplo muito interessante com relação ao início do programa Etnomatemático. Ele conta que:

\begin{abstract}
As evidências de uma espécie austrolapiteco, que viveu a cerca de 2,5 milhões de anos, mostram que essa espécie utilizou a pedra lascada para descarnar animais. $\mathrm{Na}$ hora em que esse austrolapiteco escolheu e lascou um pedaço de pedra, com o objetivo de descarnar um osso, a sua mente matemática se revelou. Para selecionar a pedra é necessário avaliar suas dimensões e, para lascá-la o necessário e o suficiente para cumprir os objetivos a que ela se destina, é preciso avaliar e comparar dimensões. Avaliar e comparar dimensões é uma das manifestações mais elementares do pensamento matemático. Um primeiro exemplo da Etnomatemática é, portanto, aquele desenvolvido pelo austrolapiteco (D’AMBROSIO, 2002, p. 33).
\end{abstract}

A matemática sempre se desenvolveu paralelamente à do povo ou das profissões, isto é, a etnomatemática. Assim, diferentes povos elaboraram meios de medir terrenos diferentemente de outros povos, e, portanto, criaram geometrias (medidas da terra) relativamente diferentes (D’AMBROSIO, 2005).

A etnomatemática é um tema que vem sendo discutido desde a década de 70 pela academia, configurada inicialmente como uma proposta de pesquisa e, a partir dos anos 90 até o tempo atual, aproxima-se cada vez mais das questões do contexto escolar. 
Para o conceito de Etnomatemática, D’Ambrosio (1990) utiliza um recurso etimológico composto por três radicais gregos: ethno, mathema e tics. Para ele Etnomatemática, é a matemática praticada por grupos culturais distintos identificados como, por exemplo, sociedades indígenas; grupo de produtores rurais, classes profissionais; grupos de crianças de certa idade; etc. Assim, para o autor, de modo geral, a Etnomatemática é uma linha de pesquisa da educação matemática que investiga as raízes culturais de ideias matemáticas, a partir da maneira como elas se dão nos diferentes grupos sociais. A Etnomatemática procura trilhar os caminhos da Antropologia, buscando identificar problemas matemáticos a partir do conhecimento do outro, na sua própria racionalidade e termos.

Nesse aspecto, o professor Orey (2006) afirma que sua tendência ao definir Etnomatemática é manter-se próximo à definição elaborada por D’Ambrosio, na qual etno + matema + tica tem um significado maior do que o simples reconhecimento do que diversas técnicas, habilidades e práticas utilizadas por grupos sociais distintos.

Considerando as diversas definições de Etnomatemática, segundo a visão dos autores presentes no contexto, a posição do pesquisador a este respeito foi manter-se próximo à concepção do professor Daniel Orey, cuja tendência ao definir Etnomatemática manteve-se próximo à definição elaborada por Ubiratan D'Ambrosio, que busca seu significado Etimológico. Assim, procurando situá-lo na proposta investigativa, toma a seguinte forma: etno - ambiente cultural no qual acontece a investigação (Comunidade Camponesa); matema a forma pela qual é explicada e compreendida a tica - técnica, a maneira pela qual a Comunidade Camponesa do MST emprega a matemática no seu cotidiano e dentro das suas necessidades.

A Etnomatemática está interessada nas culturas, nas narrativas, nas práticas sociais dos indivíduos em suas diversas atividades profissionais:

\footnotetext{
...São essas narrativas que os constituem como sujeito e como grupo, não se desqualificando, como simplificadamente alguns são levados a pensar, o conhecimento matemático tido como oficial. A Etnomatemática compreende que o acesso ao saber hegemônico é uma questão política e social (LEITES, 2005, p. 11).
}

Conforme ainda a autora, para a Etnomatemática o acesso aos conhecimentos hegemônicos é importante, já que são esses conhecimentos que são legitimados na sociedade. No entanto, essa perspectiva compreende, também, que o acesso apenas a esses conhecimentos não é o bastante, pois isso reforçaria somente um modo de racionar, e desvalorizaria os outros saberes matemáticos. Desta forma, a Etnomatemática, ao se preocupar com os saberes populares, não 
tem como intenção a glorificação da Matemática popular, mas compreender que todos os grupos produzem conhecimentos matemáticos a partir de suas práticas sociais. Sendo assim,

A matemática acadêmica, produzida pelos matemáticos, é também uma etnomatemática. Mas, ao considerar a matemática acadêmica, a Etnomatemática questiona sua pretensão de universalidade [...], pois entende que sua produção não é independente da cultura (ibidem, p. 12).

De acordo com Silva (1996), o currículo pode ser visto como um discurso que, "ao corporificar narrativas particulares sobre o indivíduo e a sociedade, nos constitui como sujeitos - e sujeitos também muito particulares" (ibidem, p.165). Essas narrativas, explícitas ou implicitamente, corporificam noções muito particulares sobre o conhecimento, as formas de organização da sociedade e os diferentes grupos sociais. São elas que nos dizem quais são os conhecimentos que podem ser considerados ou não como legítimos, quais formas de conhecimentos têm validade, o que é certo ou errado e "quais vozes são autorizadas e quais não são" (ibidem, p.165-166).

Após discorrido sobre algumas concepções de Etnomatemática, o texto seguinte traz reflexões sobre a matemática presente no contexto cotidiano e as contribuições da Etnomatemática para uma aprendizagem significativa numa perspectiva curricular.

\subsection{Do contexto cotidiano ao contexto escolar: uma postura (pedagógica) em construção etnomatemática}

Conrado (2005) afirma que a Etnomatemática tem buscado outras possibilidades para o ensino e a aprendizagem da matemática, pautado por diálogos que propiciem a troca de conhecimento e saberes entre escola/sociedade e professor/educando, abandonando a passividade, a reprodução de metodologias e a ação do professor como mero transmissor de conhecimento.

A possibilidade de incorporar práticas pedagógicas que provêm de grupos com características sociais distintas ao ensino da matemática é apontado nos Parâmetros Curriculares Nacionais (BRASIL, 1997), objetivando aprendizagens a partir dos recursos, dependências e restrições do meio no qual o aluno está inserido.

Neste aspecto, é apresentado como exemplo a compreensão e aplicação das contribuições da Etnomatemática em sala de aula, um trabalho bem contemplativo no qual são apresentadas propostas sobre como os conhecimentos matemáticos, trazidos do cotidiano do meio rural, 
podem ser utilizados no contexto escolar. Nessa perspectiva, Knijnik (2006), em sua primeira experiência docente, incorpora reflexões construídas a partir de um trabalho educativo junto ao Movimentos dos Trabalhadores Rurais Sem Terra (MST), no Rio Grande do Sul, marco teórico da Etnomatemática que trata da interface dos saberes populares e dos saberes acadêmicos, especificamente na área da matemática e das relações de poder associadas ao saber. Conforme a autora, o trabalho pautado em uma intervenção pedagógica e construção teórica, se constitui em um recorte de uma experiência pedagógica, com enfoques para os aspectos de um trabalho realizado em torno do método de conhecimento popular de medição "da terra", denominado pelos camponeses de "matemática da cubação da terra".

Assim, como a autora desconhecia os métodos populares de medição "da terra", foi "natural" aprender com aqueles alunos que os conheciam. Neste aspecto, isto significa resgatar as diferentes sequências das etapas de cálculo realizadas pelas mulheres e homens do campo, quando se defrontam com a necessidade de cubar a terra.

Desse modo, os "ensinantes", ou seja, os alunos que conheciam os métodos populares, quando indagados, enunciavam claramente tais sequências e, ao explicá-las diziam: "a gente só aprendeu como faz". Então, se justificavam quando os enunciavam, dizendo: "é assim que o pessoal faz". Muitos desses alunos contaram que aprenderam os métodos populares por meio de um processo oral de transmissão de seus familiares, simultaneamente, de uma geração anterior a deles (KNIJNIK, 2006).

Neste caso, dois métodos populares diferentes de cubação da terra são mencionados, os quais Knijnik (2006) denomina de Método do Adão e Método de Noeli (nome dos dois alunos que trouxeram as técnicas praticadas por suas comunidades). A autora, então, apresenta os dois métodos populares, na fala de cada aluno:

Método de Adão:

Bem, pessoal, esta então é a fórmula mais comum que aparece lá no interior, lá no alto da roça, né?! E vamos supor que eu sou o dono da lavoura. Eu empreitei esse quadro aqui, ó, pro indivíduo carpir. Eu disse pra ele que eu pagava três mil a quarta [6.050 metros quadrados]. Ele carpiu a área, ele mesmo passou a corda e achou essa área aqui. Então, ele mediu esta parede aqui, 90 metros, a outra 152 metros, 114 metros, 124 metros. Vocês notaram que nenhuma parede, nenhuma base, nenhuma altura tem a mesma medida, né?! Tá. Então eu fiz o seguinte aí, né: eu somei as bases e dividi por 2. Achei 138. Então, a base é 138 aqui e 138 ali, entendido? Então, eu tenho aqui as duas alturas, 114 mais 90. Achei 204; dividido por 2, 102, né?! Então, esta aqui desapareceu, e então (...) agora é só multiplicar a base vezes a altura. [Adão faz a multiplicação no quadro verde] Tá, acho esse aqui, né. 14076 metros quadrados têm essa área que ele carpiu. 
Método do Noeli:

Se a terra é do jeito de um triângulo, eles fazem assim, ó: eles pegam a base e lá em cima eles tocam um zero. Depois aplica para a terra de forma triangular os mesmos procedimentos usados por Adão.

Depois de muitos debates com seus alunos, a respeito dos dois métodos, a pesquisadora apresenta vários procedimentos para explicar a solução através da "matemática dos livros", especificamente, através da aplicação da fórmula de Heron, caso específico do método de Noeli.

O trabalho pedagógico, segundo a pesquisadora (ibidem, 1996), no processo de interpretação e decodificação dos métodos populares de cubação "da terra”, propicia o estudo de conteúdos ensinados nas escolas, como sistema métrico decimal, áreas das principais figuras planas (quadrado, retângulo, trapézio, etc.) e perímetro. Desse modo, a atividade pedagógica não busca utilizar os saberes populares apenas como uma "ponte" para os saberes científicos, há um duplo sentido: o propósito de ensinar a matemática acadêmica, socialmente legitimada, cujo domínio os próprios grupos subordinados colocam como condição para participar da vida cultural, social e econômica de um modo menos desvantajoso e, por outro lado, valorizando as práticas populares, principalmente, sendo "interpretadas e decodificadas", tendo em vista a apreensão de sua coerência interna e de sua estreita conexão com o mundo prático” (p. 62).

Depois de destacadas algumas considerações sobre o campo teórico que sustenta esse estudo, o passo seguinte apresenta alguns elementos da parte empírica da pesquisa.

\section{Parte empírica da pesquisa}

O estudo analisado nesse trabalho foi sendo configurado tendo como foco principal examinar os saberes matemáticos produzidos e praticados pela Comunidade Camponesa em suas atividades cotidianas, estabelecendo relações com o currículo escolar.

Considerando a disponibilidade e interesse de participar da pesquisa, foram convidados 06 produtores rurais: sujeito (PR.1) - "Mané Cabloco", 66 anos, analfabeto e profissão agricultor; sujeito (PR.2) - "Simão"; 65 anos, analfabeto e profissão agricultor; sujeito (PR.3) "Cumpade Pêdim", 60 anos, ensino fundamental, anos iniciais completos, e profissão agricultor; sujeito (PR.4) - "Seu Inácio", 66 anos, ensino fundamental, anos iniciais completos, e profissão agricultor; sujeito (PR.5) - "Van", 45 anos, ensino fundamental, anos 
iniciais incompletos, e profissão agricultor; sujeito (PR.6) - (Nome), 42 anos, ensino fundamental, anos iniciais completos, e profissão doméstica (“do lar”).

Os procedimentos e métodos utilizados na parte empírica da investigação foram realizados através de técnicas de inspiração etnográfica, envolvendo entrevista estruturada com perguntas abertas, sendo que algumas questões também ofereciam a oportunidade de perguntas fechadas, com o objetivo de uma melhor compreensão das respostas dadas.

As narrativas produzidas com a Comunidade Camponesa, geradas em entrevistas, centraram em questões sobre as experiências que enfatizam o uso da matemática em contextos de vida social, profissional ou doméstica, e como os conhecimentos postos em ação, pela comunidade, são desenvolvidos em suas atividades cotidianas.

A entrevista é, nas ciências sociais, o procedimento mais usual no trabalho de campo. Trata-se de uma conversa a dois com propósitos bem definidos. Etimologicamente, a palavra "entrevista" é construída a partir de duas palavras: entre (lugar ou espaço que separa duas pessoas ou coisas) e vista (ato de ver, perceber). Ou seja, a entrevista é uma comunicação bilateral e significa o "ato de perceber realizado entre duas pessoas" (RICHARDSON, 1999).

Após cada entrevista foram realizadas as transcrições dos dados pelo próprio pesquisador, que procurou seguir fielmente o que os produtores rurais entrevistados (inclusive usando a sua própria linguagem), falaram. Foi abordada, segundo Gomes (1999), a "análise de conteúdos", uma técnica que tem como principal função descobrir o que está por trás de uma prática, de uma mensagem, de uma comunicação, de uma fala, de um texto, etc. Para o autor, a análise de conteúdo, portanto, exige a utilização de critérios claramente definidos sobre registros fornecidos pelas pessoas interrogadas. Tais critérios, consideram as palavras utilizadas nas respostas as ideias ou opiniões expressas e as interpretações e justificativas apresentadas.

\section{Um recorte dos saberes matemáticos da vida cotidiana na Comunidade Camponesa}

De acordo com Silva (2005), pode-se dizer que no cotidiano da Comunidade Camponesa, percebe-se a existência de muitos saberes sendo postos em ação, os quais estão presentes na vida das pessoas a todo o momento, mas diferem, muitas vezes, daqueles aprendidos na escola. Desse modo, nas atividades cotidianas dessa comunidade costumam ser utilizados diversos saberes matemáticos ligados a medições de terra, no momento de encontrar o valor a ser pago ou recebido, na compra e venda de produtos agropecuários, adubação, cálculo do orçamento doméstico ou visando algumas construções rurais (cacimbão, aprisco, cercas, caixa 
d'água, etc.), receita caseira, compras no supermercado, o valor a ser pago em empreitadas (ou diárias) na preparação da terra para o plantio, carpinagem, etc., compra e venda em feiras livres, o troco a ser passado ou recebido.

Partindo de uma visão mais ampla do contexto cotidiano, para um olhar mais focalizado nas falas dos produtores rurais presentes na entrevista, algumas etapas parecem conter em si conhecimentos matemáticos específicos. Sendo assim, são destacados por categorias: Representações qualitativas e espaciais: aspectos da Comunidade Camponesa; Os saberes matemáticos na vida cotidiana: estratégias de sobrevivência; A matemática do produtor rural e a matemática da escola: uma questão de linguagem.

O conjunto de categorias representam a fonte dos dados coletados que norteiam a seleção das falas mais significativas (FIORENTINI e LORENZATO, 2006) da Comunidade Camponesa, sistematizada em unidades de análise ou componentes das questões relativas às referidas categorias.

$\mathrm{Na}$ entrevista realizada com os produtores rurais do MST ficou evidente a produção de saberes matemáticos em suas práticas diárias. Nesse sentido, muitas foram as regularidades encontradas no uso da matemática em contexto de vida social, profissional ou domésticas, que aparecem no desenvolvimento das atividades corriqueiras da Comunidade Camponesa. Por limitação de espaço, foi dedicado a atenção, no âmbito do presente artigo, apenas à algumas das regularidades encontradas: o uso do cálculo oral, estimativa, arredondamento e decomposição presentes nas unidades de análise que norteiam a entrevista.

Sendo assim, as regularidades encontradas nos saberes matemáticos da vida cotidiana evidenciam, no relato dos quatro sujeitos relacionados entre os seis participantes da pesquisa, o uso de procedimentos matemáticos na labuta de suas lavouras, orçamentos agropecuários e orçamentos domésticos, sendo realizados através do cálculo mental, do cálculo escrito e, quando necessário, com apoio da calculadora.

A seguir são apresentados os relatos dos quatro produtores rurais selecionados, e os procedimentos aos questionamentos dos exemplos dados presentes nas regularidades encontradas e centradas no quesito: No seu labutar com a lavoura você faz conta (cálculo) de matemática? Exemplificar, se possível, através de um exemplo de suas atividades rotineiras.

PR.1: “Sim. É conta de 'mais' e de vêiz né?... nóis faiz as conta pra sabê quanto qui é qui vai gastá na roça qui nóis vai plantá, né?” 
Exemplo: “...comprei um saco de fêjão pra plantá, gastei 150 real ...duas inxada pra fazê o sacho, gastei 15 real ...comprei uma 'matraca' (plantadeira manual) pra fazê o plantio das simente, gastei 35 real, né? ...Entonce, gastei cum tudim 200 real, né?”

Quando questionado sobre como encontrou esse valor, desenvolveu a conta num pedaço de papel fazendo assim:

Conta dele: $[100+50+30+10+5+5]$, dá 200 real, né?

Explicando como realizou a operação, disse:

“...nóis faiz logo separá tudim, né? ...adepois nóis faiz a conta de 'mais' começano do númuro qui vale mais, né?"

PR.3: "sim. É toda as conta, né? ... a de 'mais' e 'multiplicá; aparece mais vêiz, né? ...nóis faiz conta pra sabê quanta terra tem no terreno, donde vai plantá, ará, fazê o sacho ou vendê quarqué coisa qui nóis produis na terra, né?"

Exemplo: “... vendi cinquenta e três (53) ovo de vinte centavo $(R \$ 0,20)$, dá dez real e sessenta $(R \$ 10,60)$, né?"

Quando questionado a respeito do valor encontrado e introduzindo numa folha de papel, apresentou a seguinte estratégia:

Conta dele:

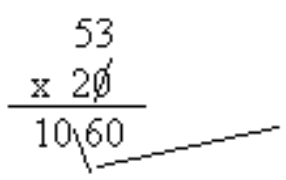

Explicando como realizou as operações, falou:

“... a conta eu cumeço cum dois, apôis cum zero vai dá zero mermo, né” 
Completando disse:

“...na vida eu sempre faço desse jeitim, apois cum zero num dá nada ...adepois o professô de Matemática do EJA insinô pra nóis, qui na conta de vêiz num careci de fazê cum zero, proquê dá zero mermo, né? ...adepois eu faço 2 vêiz 3, qui dá 6 ; e adepois 2 vêiz. 5, dá 10, e fica 1060, né? ...adepois eu dô um risco apartando os quebrado (60) e o redondo (10) [ 10,60_ ], pra mim alembrá dos centavo, né?"

Explicando onde aprendeu a fazer a conta dessa maneira, separando com um traço os dois últimos algarismos, falou:

“...aprendi na vida prática. Na iscola o professô bota um tracim, qui ele chama de vírgula, né? ...o professô gostô do jeitim qui nóis faiz, né? Ele inté dixe, se ajuda a aprendê, pode fazê desse jeitim, tá ...”

"Proseando" acrescentou:

“...na calculadora é ligêrim, e nóis podi fazê do jeitim qui o professô faiz, né?” E fez a explicação do cálculo na calculadora: “...bota 53, adepois bota o siná de vêiz ...adepois bati cum o dedo no zero e adepois no pontim, qui o professô falô qui é a vírgula, ...bota o 20, e bati o dedo no siná de iguá, fica [10.60], né? ...não pricisa separá nada cum tracim, apois o pontim é qui aparta o 10 de 60 qui é dez real e sessenta, né?”

Nos exemplos apresentados percebe-se, no caso específico do sujeito PR.1, que no estilo de cálculo realizado, segundo Silva (2005), ele usou a estratégia de adicionar, a partir da decomposição dos valores a serem computados oralmente, primeiro as ordens de maior grau. Nesse sentido, a autora exemplificapor meio de uma situação que ocorreu com um educando numa oficina de capacitação realizada por Knijnik em Viamão/RS, apresentado no excerto abaixo:

... diante de uma situação na qual necessitava realizar a operação $148+239$ [ o educando] explicou que "primeiro a gente separa tudo [100 + 40+ 80 e $200+30+9]$ e depois soma primeiro o que vale mais $[100+200,40+30,8+9]$. [...] É isto [o que vale mais] que conta". Diferentemente do algoritmo da adição, ensinado na escola, nos procedimentos orais os agricultores consideravam, antes de tudo, os valores de cada parcela que estavam em jogo e o quanto faria diferença se tratar de centenas, dezenas ou unidades, isto é, davam prioridade aos valores que contribuíam de modo mais significativo para o resultado final. 
No exemplo do sujeito PR.3, o processo apresentado pode ser justificado segundo Abreu (1988), que em seu trabalho de pesquisa com o produtor rural de cana-de-açúcar, verifica que este trabalhador rural, apesar de não usar a vírgula, parece ter regras definidas quanto às casas decimais. Assim, no caso do sujeito PR.3, como existem duas casas decimais em um dos termos, ou seja, no multiplicando, foram eliminadas duas casas no resultado.

A representatividade do sujeito PR.3 no uso da calculadora na escola pode ser considerado um avanço bastante significativo e até gratificante à determinação de um professor de matemática do EJA, ao levar para a sala de aula um artefato de cálculo bastante polêmico quanto ao seu uso nas aulas de matemática. Diante do exposto, constatou-se que alguns autores de educação matemática de jovens e adultos que estão basicamente preocupados com a requalificação, com domínio de linguagens tecnológicas por parte dos educandos, e com o papel da educação matemática na consecução desse objetivo, defendem, por exemplo, propostas de ensino com uso da calculadora, segundo Lopes, e do uso do computador, segundo Singh, citados por Fantinato (2004).

A seguir aparece mais uma resolução ligada aos aspectos que emergiram com realce na análise, por ter sido a mais original e a mais singular, que envolveu a venda de 30 animais e ganho de seiscentos reais ( $\mathrm{R} \$ 600,00)$ e, desejando saber o valor de cada animal vendido, o sujeito PR.5, assim se expressou:

“... Im 600,00 real, 100 cabi 6 vêiz e 10 cabi 60 vêiz, né?... Apois, si eu vendessi 10 bicho era 60 real pro cabeça, né?... si eu vendessi 20 bicho era 30 real pro cabeça, né?... Apois, 60 cabi 30 duas vêiz, né?...e 20 cabi três vêiz, né?... Apois, cada bicho tem de custá 20 real pro cabeça, né?"

Abreu (1988), em seu trabalho de pesquisa com produtores de cana-de-açúcar, aponta que no cálculo oral a maioria dos produtores rurais utilizava-se da correspondência e da decomposição escalar, especificamente os analfabetos.

É espetacular e curiosa a eficiência do produtor rural PR. 5 em seu procedimento para encontrar o valor unitário na venda de 30 animais que lhe rendeu seiscentos reais (R\$600,00), quando ele utiliza o conceito de divisão em partes iguais, ou seja, fração, para identificar quantas vezes um determinado múltiplo de um número cabe em partes iguais ou fração desse número, fazendo a correspondência entre o valor total da venda e seus múltiplos correspondentes, até chegar ao valor estimado de uma cabeça/animal. 
Nesse aspecto, é excelente observar que a matemática que aí se encontra possui uma espécie de codificação específica atrelada ao domínio cultural do produtor rural que pratica o fazer "matemática" do seu cotidiano. Portanto, a matemática informal que está presente na sua cultura consegue resolver a situação-problema, independentemente da matemática acadêmica. Nesse aspecto, Ubiratan D’Ambrosio (2005) enfatiza que o cotidiano está repleto de situações que envolvem habilidades matemáticas nas quais os indivíduos utilizam "instrumentos materiais e intelectuais que são próprios de sua cultura", e salienta que "é uma etnomatemática não aprendida nas escolas, mas no ambiente familiar, do trabalho e recebida de amigos e colegas”.

Por outro lado, a matemática da escola, por uma questão de tradição cultural acidental, resolve essa situação-problema empregando diretamente o algoritmo da divisão, ou usando a equação do primeiro grau, ou ainda através de uma regra de três simples, marginalizando em seu currículo o modelo apresentado pelo sujeito PR.6 e ratificando-o como erro, caso o aluno venha empregá-lo numa situação semelhante.

Os três produtores rurais utilizaram procedimentos matemáticos ligados às atividades da agropecuária, porém a exceção ocorreu com o sujeito PR.6 que não lida diretamente com a lavoura. Seu papel é de dona de casa (doméstica/do lar), ficando, então, os trabalhos e as contas referentes às atividades da lavoura aos cuidados do marido. Nesse caso, as contas desenvolvidas pelo sujeito (PR.6) estão ligadas diretamente ao orçamento doméstico e ao orçamento do criatório de pequenos animais [porco, galinha de capoeira (carne e ovo)], atividades produtivas desenvolvidas no terreiro do lote, sob a restrita responsabilidade do próprio sujeito, servindo de suporte na alimentação da família e nas pequenas despesas de casa.

PR. 6: "Não. Apois eu não trabaio na roça mermo, essa conta fica pro meu marido, né? ...eu faço conta fácí de 'mais' e de vêiz, toda veiz qui vô comprá coisas lá na cidade aqui pra casa e pro bichim qui eu crio no terreiro do loti (galinha de capoeira, porco), e pra sabê o tanto qui vô apurá na venda dos ovo de capoêra e dos pôrquim, né?"

Exemplo: “...vendi ovo de capoêra e deu quinze real e noventa $(R \$ 15,90)$...vendi galinha de capoêra e deu vinte e nove real e noventa $(R \$ 29,90)$....já sei qui vô recebê quarenta e cinco real e oitenta $(R \$ 45,80)$, né? 
Quando questionado sobre como encontrou esse valor, desenvolveu a conta numa folha de papel, fazendo assim:

$[15+29]=10+20+5+5+4=44$ real, né?

[90 + 90]= 180 e diz: "um real e oitenta né?"

$[44+1]=45$ e 80, e diz: "Quarenta e cinco real e oitenta, né?"

Explicando como realizou as operações, disse:

“...A conta eu faço logo os redondo, 15 e 29 [soma] e da 44 real, né? ...adepois eu faço os quebrado, 90 e 90 [soma], é 180, "um real e oitenta”, né? ...faço dinovo a conta dos redondo: 44 e 1 [soma], dá 45 real, né? ...sobrô dos quebrado 80, qui ajuntando dá 45 real e 80. né?

Esta estratégia de cálculo e estimativa usada pelo sujeito PR.6 representa uma prática utilizada pelas mulheres entrevistadas por Silva (2005) em seu trabalho, Saberes matemáticos produzidos por mulheres em suas atividades profissionais: um estudo de inspiração etnomatemática, que corresponde ao cálculo dos gastos a serem pagos nas compras no supermercado. Como exemplo, perguntou-se a uma das mulheres entrevistadas como ela somaria $\mathrm{R} \$ 4,50$ com $\mathrm{R} \$$ 6,25. Ela respondeu: “ A conta eu faço primeiro o 4 e o 6 [soma] e depois eu faço os centavos. Daí, 6 e 4 é 10, 60 mais 25, é 85. É 10,85 [total]”. Para a autora, nessa situação, ela inicialmente soma a parte inteira e depois a parte decimal.

Diante de tudo o que foi exposto nestes exemplos, fica evidente que o "cálculo mental" é um procedimento comum a todos os 4 produtores rurais selecionados, pois mesmo aqueles que sabem fazer no papel ou na calculadora, primeiramente, eles desenvolvem na "cabeça", para depois aplicar outra estratégia de cálculo.

Nas quatro situações-problemas apresentadas, o produtor rural atribui valores aos exemplos de suas atividades corriqueiras, pois ele tem liberdade para lidar com relações numéricas familiares. Neste caso, percebe-se que a escolaridade não influencia na estratégia adotada para solucionar as situações-problema, pois tanto os sujeitos escolarizados (casos PR.3, PR.5 e PR.6), quanto aquele que nunca frequentou a escola (caso PR.1), foram consistentes ao solucionar as questões propostas. Entretanto, a sequência à escolaridade influencia sim. Como exemplo, aparece a contribuição do EJA na aprendizagem significativa do sujeito PR.3 que, além de conhecer as quatro operações fundamentais da matemática, fez o cálculo mentalmente e escrito, e aprendeu manusear a calculadora. 
Ubirantan D’Ambrosio enfatiza que a questão pedagógica, não apenas na Etnomatemática, mas também em toda a educação, faz-se com o universo do aluno, onde está incluída a maneira de quantificar, comparar e classificar coisas que surgem espontaneamente na vida do indivíduo (D’AMBROSIO, 1996).

\section{Considerações finais}

Em síntese, esse estudo possibilitou compreender quais saberes matemáticos são manifestados e praticados em situações cotidianas, porém esses saberes não são incorporados pelo currículo escolar e continuam, de alguma maneira, ainda relegados à ignorância. Entretanto, essas práticas existem e precisam ser imediatamente resgatadas. Nesse caso, é necessário que se busquem espaços nos currículos para que se valorizem as diferenças culturais e os saberes matemáticos trazidos pelos educandos em sala de aula, pois somente assim os diferentes grupos sociais poderão compreender seus próprios modos de produzir significados matemáticos.

Nessa perspectiva, apesar de vários estudos recentes realizados por diversos e renomados educadores no campo curricular e na Etnomatemática, há ainda muito a avançar. Na grande maioria das escolas apenas a matemática formal continua sendo considerada legitima. Nessa perspectiva, D’Ambrosio (1996) enfatiza a importância de se adquirir as etnomatemáticas, pois elas darão à pessoa conhecimentos para que ela os mobilize diante dos problemas que venham enfrentar no seu dia a dia. Do mesmo modo, traz contribuição nesse aspecto ao afirmar que, embora o conhecimento seja gerado individualmente, a partir de informações captadas pelo indivíduo, são enriquecidas quando se estabelecem relações com outros indivíduos, e com outros saberes, principalmente os saberes escolares (D’AMBROSIO, 2002).

Nesse aspecto, propostas atuais para o ensino da matemática escolar vêm dando destaque ao desenvolvimento das habilidades de cálculos (mentais ou escritos, exatos e aproximados) e estimativas e, ao mesmo tempo em que estimulam o uso da calculadora, tendo em vista sua forte presença nas sociedades atuais, conferem destaque particular ao cálculo mental, estimulando sua presença nas práticas pedagógicas. No contexto brasileiro, pode-se constatar essa valorização do cálculo mental, sobretudo no Ensino Fundamental, por exemplo, no PCN - Parâmetros Curriculares Nacionais (BRASIL, 1998). 
Por outro lado, com a perspectiva da Etnomatemática, é proposto um novo olhar para o currículo, mostrando que além da matemática formal outras formas de fazer matemática podem ser legitimadas.

Deste modo, através de um olhar etnomatemático, este trabalho assinala que a matemática, como uma ação do cotidiano do ser humano no uso do desenvolvimento das suas atividades profissionais, apresenta estratégias e cálculos diferentes daqueles ensinados na escola, mas deseja, neste momento, enfatizar que o uso desse conhecimento por associação ou por comparação pode levar, ainda que com certa dificuldade, a um conhecimento mais amplo, ou seja, mais significativo.

\section{Referências}

ABREU, Guida Maria de. O uso da matemática na agricultura: o caso dos produtores de cana-de-açúcar. 1988. 209 f. Dissertação (Mestrado em Psicologia Cognitiva). Recife: UFPE, 1988

BRASIL. Secretaria de Educação Fundamental. Parâmetros curriculares nacionais: matemática. Brasília: MEC/SEF, 1997.

BRASIL. Secretaria de Educação Fundamental. Parâmetros curriculares nacionais: matemática. Secretaria de Educação Fundamental. Brasília: MEC/SEF, 1998.

CONRADO, Andréia Lunkes. A pesquisa brasileira em Etnomatemática: desenvolvimento, perspectivas, desafios. 2005. 177f. Dissertação (Mestrado em Educação), São Paulo: USP, 2005

D'AMBROSIO, Ubiratan. Etnomatemática: arte ou técnica de explicar e conhecer. 4. ed. São Paulo: Ática, 1990. 88p.

1996.

Educação Matemática: da teoria a prática. Campinas, São Paulo: Papirus,

Etnomatemática: elo entre as tradições e a modernidade. Belo Horizonte:

Autêntica, 2002. 112p. (Coleção Tendência em Educação Matemática).

Volta ao Mundo em 80 matemáticas. Revista Scientific American Brasil,

n. 11. São Paulo: Ediouro, 2005. pp. 6-9. Edição especial.

DELFINO, Ana Maria Aparecida. A Etnomatemática em uma sala do EJA: a experiência de um pedreiro. 2007. 213 f. Dissertação (Mestrado em Educação Matemática). São Paulo: PUC, 2007. 
FANTINATO, Maria Cecília C. B. A construção de saberes matemáticos entre jovens e adultos do Morro de São Carlos. Revista Brasileira de Educação, n. 27, pp. 1-14. Rio de Janeiro: ANPEd, 2004.

FIORENTINI, Dario e LORENZATO, Sérgio. Investigação em educação matemática: percursos teóricos e metodológicos. 3. ed. rev. Campinas, SP: Autores Associados, 2009. 228 p. (Coleção Formação de Professores).

GOMES, R. A análise de dados em pesquisa qualitativa. In: MINAYO, M. C. S. (Org.). Pesquisa social: teoria, método e criatividade. Petrópolis: Vozes, 1999.

KNIJNIK, Gelsa. Currículo, etnomatemática e educação popular: um estudo em um assentamento sem-terra. In: Currículo sem fronteiras, v. 3, n. 1, pp. 96-110, jan/jun. 2003.

Educação matemática, culturas e conhecimento na luta pela terra. Santa Cruz do Sul: EDUNISC, 2006. p. 64-10. 239p.

LEITES, Carmem Becker. Etnomatemática e currículo escolar: problematizando uma experiência pedagógica com alunos de $5^{\mathrm{a}}$ série. 2005. 137 f. Dissertação de Mestrado. Programa de Pós-Graduação em Educação da UNISINOS. São Leopoldo, 2005.

OREY, Daniel Clark. Etnomatemática: papel, valor e significado. In: DOMITE, Maria do Carmo Santos: FERREIRA, Rogério; RIBEIRO, José Pedro Machado (Org.). Etnomatemática: papel, valor e significado. 2. ed. Porto Alegre: Zouk, 2006.

RICHARDSON, Roberto Jarry. Pesquisa social: métodos e técnicas. 3. ed. São Paulo: Atlas, 1999. 334p.

ROSA, Milton; OREY, Daniel Clark. Tendências atuais da etnomatemática como um programa: rumo à ação pedagógica. In: Revista Zetetiké, São Paulo: UNICAMP, v. 13, n. 23, jul / dez. 2004.

SANTOS, Sueli dos. O ensino da matemática com significação nos anos iniciais da educação básica. Natal: UFRN, 2007.

SILVA, Fabiana Boff de Souza da. Saberes matemáticos produzidos por mulheres em suas atividades profissionais: um estudo de inspiração etnomatemática. Porto Alegre: UNISINOS, 2005.

SILVA, Tomaz Tadeu da. Identidade Terminais: As transformações na política da pedagogia e na pedagogia da política. Petrópolis, RJ: Vozes, 1996. 